University of Wollongong

Research Online

Faculty of Engineering and Information

Faculty of Engineering and Information

Sciences - Papers: Part A

Sciences

$1-1-2016$

Occurrence of trace organic contaminants in wastewater sludge and their removals by anaerobic digestion

\author{
Shufan Yang \\ University of Wollongong, sy527@uowmail.edu.au \\ Faisal I. Hai \\ University of Wollongong, faisal@uow.edu.au \\ William E. Price \\ University of Wollongong, wprice@uow.edu.au \\ James McDonald \\ University of New South Wales \\ Stuart J. Khan \\ University of New South Wales, s.khan@unsw.edu.au
}

See next page for additional authors

Follow this and additional works at: https://ro.uow.edu.au/eispapers

Part of the Engineering Commons, and the Science and Technology Studies Commons

Research Online is the open access institutional repository for the University of Wollongong. For further information contact the UOW Library: research-pubs@uow.edu.au 


\title{
Occurrence of trace organic contaminants in wastewater sludge and their removals by anaerobic digestion
}

\author{
Abstract \\ This study aims to evaluate the occurrence of trace organic contaminants (TrOCs) in wastewater sludge \\ and their removal during anaerobic digestion. The significant occurrence of 18 TrOCs in primary sludge \\ was observed. These TrOCs occurred predominantly in the solid phase. Some of these TrOCs (e.g. \\ paracetamol, caffeine, ibuprofen and triclosan) were also found at high concentrations $(>10,000$. $\mathrm{ng} / \mathrm{L})$ in \\ the aqueous phase. The overall removal of TrOCs (from both the aqueous and solid phase) by anaerobic \\ digestion was governed by their molecular structure (e.g. the presence/absence of electron withdrawing/ \\ donating functional groups). While an increase in sludge retention time (SRT) of the digester resulted in a \\ small but clearly discernible increase in basic biological performance (e.g. volatile solids removal and \\ biogas production), the impact of SRT on TrOC removal was negligible. The lack of SRT influence on TrOC \\ removal suggests that TrOCs were not the main substrate for anaerobic digestion.

\section{Disciplines} \\ Engineering | Science and Technology Studies

\section{Publication Details} \\ Yang, S., Hai, F. I., Price, W. E., McDonald, J., Khan, S. J. \& Nghiem, L. D. (2016). Occurrence of trace \\ organic contaminants in wastewater sludge and their removals by anaerobic digestion. Bioresource \\ Technology, 210 153-159. \\ Authors \\ Shufan Yang, Faisal I. Hai, William E. Price, James McDonald, Stuart J. Khan, and Long D. Nghiem
}


1

\section{Submitted to Bioresource Technology}

November 2015

Shufan Yang ${ }^{\text {a }}$, James McDonald ${ }^{\mathrm{c}}$, Faisal I. Hai ${ }^{\mathrm{a}}$, William E. Price ${ }^{\mathrm{b}}$, Stuart J. Khan ${ }^{\mathrm{c}}$, Long D. Nghiem ${ }^{a^{*}}$

${ }^{\text {a }}$ Strategic Water Infrastructure Lab, School of Civil, Mining and Environmental Engineering,

9 University of Wollongong, Australia

10 b Strategic Water Infrastructure Lab, School of Chemistry, University of Wollongong

11 Australia

$12{ }^{\mathrm{c}}$ School of Civil and Environmental Engineering, University of New South Wales, NSW 13 2052, Australia 


\section{Abstract}

This study aims to evaluate the occurrence of trace organic contaminants (TrOCs) in wastewater sludge and their removal during anaerobic digestion. The significant occurrence of 18 TrOCs in primary sludge was observed. These TrOCs occurred predominantly in the solid phase. Some of these TrOCs (e.g. paracetamol, caffeine, ibuprofen and triclosan) were also found at very high concentration (>10,000 ng/L) in the aqueous phase. The overall removal of TrOCs (from both the aqueous and solid phase) by anaerobic digestion was governed by their molecular structure (e.g. the presence/absence of electron withdrawing/donating functional groups). While an increase in sludge retention time (SRT) of the digester resulted in a small but clearly discernible increase in basic biological performance (e.g. volatile solids removal and biogas production), the impact of SRT on TrOC removal was negligible. The lack of SRT influence on TrOC removal suggests that TrOCs were not the main substrate for anaerobic digestion.

Keyword: Anaerobic digestion, primary sludge, sludge retention time (SRT), trace organic contaminants, molecular structure.

\section{Introduction}

Wastewater treatment involves the settling of solid materials and transformation of dissolved and suspended organic matter to sludge. During wastewater treatment, a large volume of sludge is produced. The EU generates about 10 million tonnes of dry sludge each year (Fytili \& Zabaniotou, 2008). In Australia, dry sludge production from wastewater treatment increased by about 3\% each year from 0.3 million tonnes in 2010 to 0.33 million tonnes in 2013 (Semblante et al., 2014). Thus, the production of excess sludge from wastewater treatment is a vexing problem and necessitates effective management strategies.

Wastewater sludge has a high organic content and a host of pathogenic vectors. As a result, wastewater sludge must be treated or stabilised prior to environmental disposal. The organic content in wastewater sludge can be converted into energy through a range of technologies including anaerobic digestion (Karthikeyan \& Visvanathan, 2013) and microbial fuel cell (Oh et al., 2014). Amongst them, anaerobic digestion is probably the most widely used technology for wastewater sludge treatment (Chernicharo et al., 2015; Kim et al., 2011).

During the anaerobic digestion process, a consortium of microbes metabolizes and converts organic substances into biogas in the absence of oxygen. Anaerobic digestion can achieve a sludge solid reduction of 40 to 60\% (Malina \& Pohland, 1992) and generate methane gas as a renewable fuel. The digested sludge from anaerobic digestion can be used as fertilizers and soil conditioners in agriculture (Elliott et al., 1990). 
Application of the digested sludge on the land is a sustainable option because it enables the recovery of important nutrients and adds economic value to what is conventionally perceived as waste. Nevertheless, recent discovery of the widespread occurrence of trace organic contaminants (TrOCs) in municipal wastewater suggests that some of these compounds can be transferred to sludge during wastewater treatment (Citulski \& Farahbakhsh, 2010; Semblante et al., 2015). These TrOCs include pesticides, industrial chemicals, components of consumer products, pharmaceuticals and personal care products, hormones, and other organic pollutants that are regularly released into municipal wastewater by anthropogenic activities (Luo et al., 2014).

TrOCs have been commonly found in municipal wastewater at very low concentrations (Verlicchi \& Zambello, 2015). At a sufficient concentration, some of these TrOCs have the potential to cause chronic disorders in animals and humans. Several countries have already imposed controls on certain TrOCs such as nonylphenol and nonylphenol ethoxylates, polychlorinated biphenyls, polychlorinated dibenzo-p-dioxins and dibenzo-p-furans. However, a clear approach to address TrOCs in digested sludge has not yet been developed (Smith, 2009).

Some TrOCs are lipophilic. In other words, they can be transferred to the solid phase during primary and secondary clarification (Clarke \& Smith, 2011), resulting in significantly higher concentrations (several $\mu \mathrm{g} / \mathrm{kg}$ dry weight or more) in sludge than wastewater. Persistent TrOCs have the potential to bioaccumulate during land application and, if left unchecked, may impose adverse risk to humans and the ecosystem.

Antibiotics and other pharmaceutically active compounds were amongst the most investigated TrOCs in digested sludge. Trimethoprim, sulfamethoxazole, ciprofloxacin and doxycycline were notable antibiotics detected at the low $\mathrm{mg} / \mathrm{kg}$ dry weight range in digested sludge from Swedish wastewater treatment plants (Golet et al., 2003; Lindberg et al., 2005). Ciprofloxacin and diphenhydramine were also detected in more than 80 sludge samples across the USA (Grumbles, 2009). In Japan, Narumiya et al. (2013) reported the occurrence of 45 TrOCs in the digested sludge. Concentrations of several compounds (e.g. ofloxacin, triclosan and triclocarban) exceeded $1 \mathrm{mg} / \mathrm{kg}$ dry sludge (Narumiya et al., 2013). Several personal care products including triclosan and triclocarban have also been reported to accumulate in anaerobically digested sludge to a high concentration (Heidler \& Halden, 2007; Heidler et al., 2006).

Most previous studies concerning anaerobic treatment have focused specifically on the removal of TrOC from the aqueous (water) phase. Thus, findings from these studies are not 
readily applicable to anaerobic digestion of wastewater sludge. Indeed, results from recent studies (Carballa et al., 2007; Hernandez-Raquet et al., 2007; Malmborg \& Magner, 2015; Narumiya et al., 2013) examining the removal of TrOCs from both aqueous and solid phases by anaerobic digestion show that the overall removal efficiency could be lower compared to studies that only reported TrOC removal from the aqueous phase.

It is noteworthy that most previous studies involved the spiking (artificial addition) of TrOCs to the feed sludge at elevated concentrations. Malmborg and Magner (2015) studied the fate of 14 different TrOCs during the anaerobic digestion by spiking each compound at $50 \mathrm{mg} / \mathrm{L}$ into the sludge. They showed that several compounds (e.g. trimethoprim, citalopram, and furosemide) were well removed by anaerobic digestion. However, several others including fluoxetine and carbamazepine were persistent to anaerobic digestion. Similar results were reported by Carballa et al. (2007) who added TrOCs to feed sludge at concentrations between 4 and $400 \mu \mathrm{g} / \mathrm{L}$. Narumiya et al. (2013) was probably the only group of authors who have monitored the environmental concentrations of TrOCs in the feed sludge. Narumiya et al. (2013) showed that 4 out of 26 compounds, namely, sulfamethoxazole, trimethoprim, caffeine and acetaminophen detected in the thickened sludge were well removed by anaerobic digestion while most of the remaining compounds were not significantly removed.

This study aims to reveal the occurrence and fate of TrOCs during anaerobic digestion of primary sludge. Basic biological performance of anaerobic digesters at a range of sludge retentiontime (SRT) is systematically examined. TrOCs concentrations in the aqueous and solid phase from both primary and digested sludge are quantified to examine their fate during anaerobic digestion.

\section{Materials and Methods}

\subsection{Wastewater sludge}

Anaerobically digested sludge and primary sludge were taken from a full scale wastewater treatment plant in New South Wales (Australia) as inoculum and feed, respectively. The primary sludge was stored at $4{ }^{\circ} \mathrm{C}$ for a maximum of 2 weeks before fresh sludge was collected again. The total solids (TS) content of this primary sludge was $25.7 \pm 6.6 \mathrm{~g} / \mathrm{L}$ (average \pm standard deviation of eight samples). The ratio of volatile solids (VS) over TS (VS/TS) of this primary sludge was stable $(0.89 \pm 0.03)$ during the current study. $\mathrm{pH}$ value of the primary sludge was in the range of 5.35 to 5.59 .

\subsection{Anaerobic digester}


Three identical anaerobic digesters were used. Each digester (Supplementary Data Figure S1) consists of a 28 L conical shape stainless steel reactor, a peristaltic hose pump (DULCO ${ }^{\circledR}$ Flex from ProMinent Fluid Controls, Australia), a thermal couple with temperature gauge, a custom made gas counter, and a gas trap for biogas sampling. Hot water flowing inside a rubber hose wrapping around the digester was used for heating. The entire reactor was insulated by polystyrene foam. The temperature of the digester was maintained at $35.0 \pm 0.5^{\circ} \mathrm{C}$ by regulating the temperature inside the rubber hose using a temperature control unit (Neslab RTE 7, Thermo Fisher Scientific, Newington, USA). When necessary, biogas from the gas counter can be directed to a gas trap for biogas composition analysis.

\subsection{Experimental protocol}

Each digester was seeded with anaerobically digested sludge at the beginning of the experiment. The peristaltic pump was operated continuously at the flow rate of $60 \mathrm{~L} / \mathrm{h}$ to provide sufficient sludge mixing. The active volumes of all three digesters were maintained at $20 \mathrm{~L}$ throughout the experiment. The SRT of the three digesters were set at 15, 20 and $30 \mathrm{~d}$, respectively, by withdrawing and feeding a predetermined volume of sludge each day. The digesters were first stabilized for two weeks. Digested sludge and feed samples were then collected for analysis over 12 weeks of continuous operation.

\subsection{Analytical methods}

\subsubsection{Biogas production and composition}

Biogas production was monitored using an online gas counter. Biogas composition analysis was conducted every week. Approximately $1 \mathrm{~L}$ of biogas was collected in the gas trap (Supplementary Data Figure S1). A portable gas analyser (GA5000 gas analyser, Geotechnical Instruments (UK) Ltd, England) was then used for biogas composition analysis

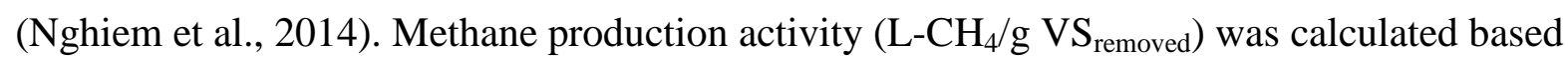
on the methane composition in biogas and the biogas production rate.

\subsubsection{Sludge characteristics}

Sludge samples were taken weekly from each digesters as well as primary sludge. The tested sludge characterization parameters included TS, VS, total chemical oxygen demand (tCOD), soluble chemical oxygen demand (sCOD), $\mathrm{pH}$, and alkalinity. The $\mathrm{pH}$ of the sludge samples was measured by a $\mathrm{pH}$ meter (Orion $4 \mathrm{Star} \mathrm{pH}$ and conductivity portable meter, Thermo Scientific, Australia). TS, VS, and alkalinity were measured in accordance to the standard methods (Eaton et al., 2005). COD was measured following the US-EPA Method 8000 using high range COD vials (HACH, USA). The supernatant used for measurement of sCOD was 
obtained by centrifuging sludge sample at 3720xg for 10 minutes (Allegra X-12R centrifuge, Beckman Coulter, Australia), and then filtering through $1 \mu \mathrm{m}$ glass microfiber filter paper (Filtech, Australia).

\subsubsection{TrOC sample preparation and analysis}

Duplicated TrOCs samples were taken from digested sludge and primary sludge approximately every 7 days. The concentration of TrOCs in the sludge phase was determined according to a method previously described by Wijekoon et al. (2014). Briefly, analytes were separated using an Agilent (Palo Alto, CA, USA) 1200 series high performance liquid chromatography (HPLC) systemon a Luna C18 (2) column (Phenomenex, Torrence CA, USA). Peaks were identified and quantified by mass spectrometry using an API 4000 triple quadrupole mass spectrometer (Applied Biosystems, Foster City, CA, USA) equipped with a turbo-V ion source employed in both positive and negative electro-spray modes. The limit of quantification of this analytical technique was $20 \mathrm{ng} / \mathrm{L}$ for bisphenol A, $10 \mathrm{ng} / \mathrm{L}$ for caffeine, triclocarban, and diuron, and $5 \mathrm{ng} / \mathrm{L}$ for all other compounds reported in this study.

Sludge samples were centrifuged at 3720xg for 10 minutes (Alleegra X-12R, Beckman Coulter, USA) to obtain solid pellets and supernatant for further analysis. Supernatant (50 mL) from the sludge sample was diluted to $500 \mathrm{~mL}$ by Milli-Q water, and filtered by $1 \mu \mathrm{m}$ and 0.7 $\mu \mathrm{m}$ pore size glass microfiber filter paper for solid phase extraction (SPE).The pellets from the sludge sample were freeze-dried for $10 \mathrm{~h}$ using the Alpha 1-2 LDplus Freeze Dryer (Christ GmbH, Germany). The dried sample was then grounded to powder and $0.5 \mathrm{~g}$ powder was transferred to a $13 \mathrm{~mL}$ glass vial (with cap) for extraction. Methanol (10 mL) was added to the vial, mixed thoroughly by vortex mixer (VM1, Ratek, Australia), and ultrasonicated for 10 minutes at $40^{\circ} \mathrm{C}$. The sample was centrifuged at $3720 \mathrm{xg}$ for 10 minutes, and the supernatant was collected. A solvent made of dichloromethane and methanol (1:1, v/v) (10 $\mathrm{mL}$ ) was added to the remaining sludge, and supernatant was collected by following the previous processes. The supernatant from both steps were combined, diluted into $500 \mathrm{~mL}$ by Milli-Q water, and filtered by $1 \mu \mathrm{m}$ and then $0.7 \mu \mathrm{m}$ pore size glass microfiber filter paper for subsequent SPE.

The extracted liquid samples from both the sludge supernatant and solid were spiked with surrogate (50 $\mu \mathrm{L}$ per sample) containing 36 isotopically labelled standards (Supplementary Data Table S2) for method recovery and detection level determination. The liquid samples were then loaded onto the HLB cartridges conditioned with $5 \mathrm{~mL}$ methyl tert-butyl ether, 5 $\mathrm{mL}$ methanol, and 2 x $5 \mathrm{~mL}$ Milli-Q water at the flow rate of approximately $15 \mathrm{~mL} / \mathrm{min}$. After 
concentrating to $1 \mathrm{~mL}$, eluted samples were subjected to gas chromatography tandem mass spectrometry (GC-MS/MS) analysis (McDonald et al., 2012).

\subsubsection{TrOC mass balance}

The inlet TrOC concentration can be denoted as:

$$
C_{i n}=X_{i n} \times T S_{i n}+S_{i n}
$$

where $\mathrm{C}_{\text {in }}$ is the total inlet concentration (ng/L), $\mathrm{X}_{\text {in }}$ is the TrOC concentration in the solid phase of primary sludge (ng/g dry sludge), $\mathrm{TS}_{\text {in }}$ is the total solid concentration of primary sludge $(\mathrm{g} / \mathrm{L})$, and $\mathrm{S}_{\mathrm{in}}$ is the TrOC concentration in the aqueous phase of primary sludge $(\mathrm{ng} / \mathrm{L})$. Similarly in the outlet sludge, the concentration of TrOC can be calculated as

$C_{\text {out }}=X_{\text {out }} \times T S_{\text {out }}+S_{\text {out }}$

where $\mathrm{C}_{\text {out }}$ is the total outlet concentration (ng/L), $\mathrm{X}_{\text {out }}$ is the TrOC concentration in the solid phase of digested sludge (ng/g dry sludge), TS out is the total solid concentration of digested sludge (g/L) and $\mathrm{S}_{\text {in }}$ is the TrOC concentration in the aqueous phase of digested sludge (ng/L). Thus the mass balance for TrOC concentration can be presented as

$C_{\text {in }}=C_{\text {out }}+C_{\text {bio }}$

where $\mathrm{C}_{\mathrm{bio}}$ is the portion of TrOC that has been biodegraded.

\section{Results and discussion}

\subsection{Anaerobic digester performance}

Biogas production rate and composition are key parameters to examine the anaerobic digester performance. As the SRT was increased from 15 to $30 \mathrm{~d}$, a notable increased in methane

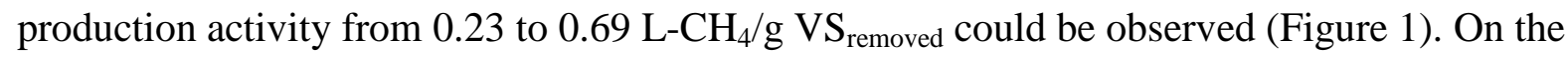
other hand, biogas composition was not affected by the digester SRT. Indeed, all biogas samples were composed of approximately $60 \%$ methane and $40 \%$ carbon dioxide regardless of the digester SRT.

[FIGURE 1]

Corresponding to the observed increase in methane production activity due to increasing SRT, a small nevertheless discernible improvement in the reduction of both TS and VS can be observed (Table 1). As expected, the reduction of VS was consistently higher than that of TS. As the SRT increased from 15 to 30 days, VS reduction increased from 69.3 to $75.8 \%$. A similar observation could be made regarding the removal of tCOD. Indeed, tCOD removal increased from roughly 70 to $77 \%$ when SRT increased from 15 to $30 \mathrm{~d}$ (Table 1). On the 
other hand, the removal of SCOD was not significantly affected by SRT. It should be noted that the soluble COD fraction was relatively small (approximately 2,000 $\mathrm{mg} / \mathrm{L}$ ) compared to the total COD content of the feed (approximately 35,000 mg/L). Overall, results presented in Table 1 show notable improvement in basic performance parameters by increasing the SRT beyond 15 days, which can be attributed to the enhanced methanogenic population and activity at high SRT (Rubia et al., 2006).

\section{[TABLE 1]}

It is noteworthy that the alkalinity at $\mathrm{pH}=4.5$ (Supplementary Data Figure S3) and $\mathrm{pH}$ value of each digester were also monitored throughout the experiment. The mixed liquor $\mathrm{pH}$ values of all three digesters were in the range typical for normal anaerobic digestion (i.e. 7.45 to

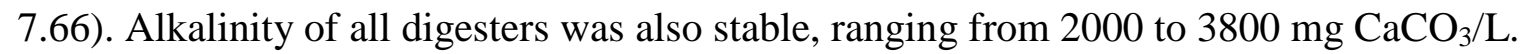
Over all, all three digesters were in good condition throughout the current study. There was no indication of volatile fatty acid or ammonia accumulation in the digesters.

\subsection{TrOC occurrence in primary sludge}

Of the 36 TrOCs monitored in this study (Supplementary Data Table S2), 18 compounds were consistently detected in all primary sludge samples (Table 2). Their concentrations as well as distribution between the aqueous and solid phase varied significantly. Of these TrOCs, paracetamol, caffeine, ibuprofen and triclosan showed the highest concentrations $(>10,000$ $\mathrm{ng} / \mathrm{L}$ ) in the aqueous phase. The prevalent occurrence of these TrOCs in primary sludge can be attributed to their widespread use in our modern society. Paracetamol and ibuprofen are over-the-counter analgesic and antipyretic drugs. Triclosan is an antibacterial/antifungal agent widely used in soap, detergent, and toothpaste. Caffeine is a stimulant occurring naturally in tea and coffee. Overall, their frequent use in daily life is consistent with the accumulation of these TrOCs in primary sludge (Stasinakis, 2012).

\section{[TABLE 2]}

All 18 TrOCs detectable in this study occurred predominantly in the solid phase. In all cases, their concentration in the solid phase (in $\mathrm{ng} / \mathrm{Kg}$ ) was much higher than that in the aqueous phase (in ng/L). pH value of the primary sludge was in the range of 5.35 to 5.59 (Section 2.1). Thus, $\log \mathrm{D}$ value at $\mathrm{pH} 5$ was used to determine the hydrophobicity of these TrOCs. The distribution of these TrOCs in the solid phase increased as their log D value increased (Table 2). For all TrOCs with moderate hydrophobicity ( $\log \mathrm{D}>2$ ), 72 to $99 \%$ of the total mass partitioned in the solid phase (Table 2). In line with recent studies concerning anaerobic treatment of wastewater (Monsalvo et al., 2014; Wang et al., 2014; Wijekoon et al., 2015), 
the results here indicate the need to systematically investigate the fate and transport of TrOCs in the liquid and solid phases during anaerobic digestion.

The high standard deviation shown in Table 2 also indicates a significant temporal variation in their occurrence in primary sludge. The SRT values (15 to 30 days) used in this study were comparable or significantly higher than the sampling interval (Section 2.1). Thus, some variation in the calculated removal efficiency would be expected.

\subsection{The fate of TrOCs during the anaerobic digestion}

Concentrations of TrOCs in the aqueous and solid phase before and after anaerobic digestion with SRT of 15, 20, and 30 days are shown in Figures 2 and 3. TrOC removals from both the aqueous and solid phase varied greatly. For example, atenolol, caffeine, trimethoprim, paracetamol and naproxen were well removed from the aqueous phase. These compounds were also effectively removed from the solid phase by anaerobic digestion. On the other hand, several TrOCs including carbamazepine, gemfibrozil, verapamil, amitriptyline, diuron, clozapine, bisphenol A, triclosan, and triclocarbon showed no or only negligible removal from either the liquid or the solid phase.

\section{[FIGURE 2]}

\section{[FIGURE 3]}

$\mathrm{pH}$ values of the primary sludge was from 5.35 to 5.59, while the digested sludge $\mathrm{pH}$ was in the range of 7.46 to 7.66 . This $\mathrm{pH}$ increase during anaerobic digestion facilitates the transfer of some TrOCs between the aqueous and solid phase, particularly those that are ionisable with a pKa value in the vicinity of pH 5 to 7. A notable example is ibuprofen. With a pKa value of 4.9, ibuprofen can change from a moderately hydrophobic to a hydrophilic (increasing solubility in water) form. As a result, while there was a notable decrease in ibuprofen concentration in the solid phase due to anaerobic digestion, a small but discernible increase in ibuprofen concentration in the aqueous phase can be observed. To account for the possible transfer from the solid to aqueous phase, mass distribution of each TrOC between the two phases and biodegradation after anaerobic digestion under different SRT is also presented in Figure 4.

As noted above, hydrophobicity (measured by log D value) of TrOCs is a key factor governing their distribution between the solid and aqueous phase. Nevertheless, unlike several previous studies (Monsalvo et al., 2014; Tadkaew et al., 2011; Wijekoon et al., 2015) where removal from the aqueous phase was the primary concern, results in Figure 4 show that the overall TrOC removal by anaerobic digestion was not significantly influenced by their 
hydrophobicity. On the other hand, the qualitative biodegradation prediction framework proposed by Tadkeaw et al. (2010) and Wijekoon et al. (2015) for aerobic and anaerobic membrane bioreactors, respectively, can be used to explain the removal data in Figure 4.

TrOCs with strong electron donating functional groups were readily degradable by anaerobic digestion (Supplementary Data Table S4). Examples of these strong electron donating functional groups are provided in Supplementary Data Table S5. As a result, atenolol, caffeine, trimethoprim, paracetamol, naproxen, and amitriptyline were well removed by anaerobic digestion (Figure 4). On the other hand, TrOCs with strong electron withdrawing functional groups were resistant to anaerobic digestion (Supplementary Data Table S4). Compounds in this group include diclofenac, gemfibrozil, carbamazepine, diuron, and triclocarban given the presence of their chloro and amide moieties which are strong electron withdrawing functional groups (Supplementary Data Table S5). It is noted that no removal of bisphenol A was recorded in this study despite the presence of a strong electron donating functional group (hydroxyl). The reason for this observation cannot be confirmed but the release of bisphenol A from plastic component of the experimental system is a plausible explanation.

\section{[FIGURE 4]}

Data presented in Figures 2-4 show no or only marginal improvement in the removal of TrOCs when the SRT increased from 15 to 30 days. These results are in good agreement with a previous study by Carballa et al. (2007) who did not observe any notable increase in the removal of several hydrophilic organic compounds as the SRT value increased from 10 to 30 $\mathrm{d}$. The relative independence between SRT and TrOC removal could be attributed to the fact that they are not the main substrate for the anaerobic digestion process. It is also possible that the improvement in TrOC removal with increasing SRT was not significant and was masked by the variation in feed concentration as discussed in section 3.2.

\section{Conclusion}

In this study, 18 trace organic contaminants (TrOCs) were consistently detected in all primary sludge samples. These TrOCs occurred predominantly in the solid phase. The overall removal of TrOCs (from both the aqueous and solid phase) and their fate during anaerobic digestion were governed by their molecular structure (e.g. the presence/absence of electron withdrawing or donating functional groups). An increase in sludge retention time (SRT) of the digester resulted in a small but clearly discernible increase in basic biological performance (e.g. volatile solids removal and biogas production). On the other hand, the impact of SRT on TrOC removal was negligible. 


\section{Reference}

[1] Carballa, M., Omil, F., Ternes, T., Lema, M.J. 2007. Fate of pharmaceutical and personal care products (PPCPs)during anaerobic digestion of sewage sludge. Water Research, 41, 2139-2150.

[2] Chernicharo, C.A.L., van Lier, J.B., Noyola, A., Bressani Ribeiro, T. 2015. Anaerobic sewage treatment: state of the art, constraints and challenges. Reviews in Environmental Science and Bio/Technology, 1-31.

[3] Citulski, J.A., Farahbakhsh, K. 2010. Fate of endocrine-active compounds during municipal biosolids treatment: A review. Environmental Science \& Technology, 44, 8367-8376.

[4] Clarke, O.B., Smith, R.S. 2011. Review of 'emerging' organic contaminants in biosolids and assessment of international research priorities for the agricultural use of biosolids. Environment International, 37, 226-247.

[5] Eaton, D.A., Clesceri, S.L., Greenberg, E.A. 2005. Standard Methods for Examination of Water \& Wastewater $21^{\text {st }}$ ed. American Public Health Association

[6] Elliott, A.H., Dempsey, A.B., Hamilton, W.D., DeWolfe, R.J. 1990. Land application of water treatment sludges: impacts and management. American Water Works Association, Denver.

[7] Fytili, D., Zabaniotou, A. 2008. Utilization of sewage sludge in EU application of old and new methods—A review. Renewable and Sustainable Energy Reviews, 12, 116-140.

[8] Golet, E.M., Xifra, I., Siegrist, H., Alder, A.C., Giger, W. 2003. Environmental exposure assessment of fluoroquinolone antibacterial agents from sewage to soil. Environmental Science \& Technology, 37, 3243-3249.

[9] Grumbles, B.H. 2009. Targeted national sewage sludge survey statistical analysis report. United states environmental protection agency office of water.

[10] Heidler, J., Halden, U.R. 2007. Mass balance assessment of triclosan removal during conventional sewage treatment. Chemosphere, 66, 362-369.

[11] Heidler, J., Sapkota, A., Halden, R.U. 2006. Partitioning, persistence, and accumulation in digested sludge of the topical antiseptic triclocarban during wastewater treatment. Environmental Science \& Technology, 40, 3634-3639. 
[12] Hernandez-Raquet, G., Soef, A., Delgenès, N., Balaguer, P. 2007. Removal of the endocrine disrupter nonylphenol and its estrogenic activity in sludge treatment processes. Water Research, 41, 2643-2651.

[13] Karthikeyan, O.P., Visvanathan, C. 2013. Bio-energy recovery from high-solid organic substrates by dry anaerobic bio-conversion processes: a review. Reviews in Environmental Science and Biotechnology, 12, 257-284.

[14] Kim, J., Novak, T.J., Higgins, J.M. 2011. Multistaged anaerobic sludge digestion processes. Journal of Environmental Engineering 137, 746-753.

[15] Lindberg, R.H., Wennberg, P., Johansson, M.I., Tysklind, M., Andersson, B.A.V. 2005. Screening of human antibiotic substances and determination of weekly mass flows in five sewage treatment plants in Sweden. Environmental Science \& Technology, 39, 3421-3429.

[16] Luo, Y., Guo, W., Ngo, H.H., Nghiem, L.D., Hai, F.I., Zhang, J., Liang, S., Wang, X.C. 2014. A review on the occurrence of micropollutants in the aquatic environment and their fate and removal during wastewater treatment. Science of the total environment, 473-474, 619-641.

[17] Malina, F.J., Pohland, G.P. 1992. Design of anaerobic processes for the treatment of industrial and municipal wastes. Technomic publishing company, Lancaster.

[18] Malmborg, J., Magner, J. 2015. Pharmaceutical residues in sewage sludge: Effect of sanitization and anaerobic digestion. Journal of Environmental Management, 153, 110.

[19] McDonald, A.J., Harden, B.N., Nghiem, D.L., Khan, J.S. 2012. Analysis of Nnitrosamines in water by isotope dilution gas chromatography-electron ionisation tandem mass spectrometry. Talanta, 99, 146-154.

[20] Monsalvo, V.M., McDonald, J.A., Khan, S.J., Le-Clech, P. 2014. Removal of trace organics by anaerobic membrane bioreactors. Water Research, 49, 103-112.

[21] Narumiya, M., Nakada, N., Yamashita, N., Tanaka, H. 2013. Phase distribution and removal of pharmaceuticals and personal care products during anaerobic sludge digestion. Journal of Hazardous Materials, 260, 305-312.

[22] Nghiem, L.D., Manassa, P., Dawson, M., Fitzgerald, S.K. 2014. Oxidation reduction potential as a parameter to regulate micro-oxygen injection into anaerobic digester for 
reducing hydrogen sulphide concentration in biogas. Bioresource Technology, 173, 443-447.

375

[23] Oh, S.-E., Yoon, J.Y., Gurung, A., Kim, D.-J. 2014. Evaluation of electricity generation from ultrasonic and heat/alkaline pretreatment of different sludge types using microbial fuel cells. Bioresource Technology, 165, 21-26.

[24] Rubia, d.l.M.A., Perez, M., Romero, I.L., Sales, D. 2006. Effect of solids retention time (SRT) on pilot scale anaerobic thermophilic sludge digestion. Process Biochemistry, 41, 79-86.

[25] Semblante, G.U., Hai, F.I., Huang, X., Ball, A.S., Price, W.E., Nghiem, L.D. 2015. Trace organic contaminants in biosolids: Impact of conventional wastewater and sludge processing technologies and emerging alternatives. Journal of hazardous materials, $300,1-17$.

[26] Semblante, G.U., Hai, F.I., Ngo, H.H., Guo, W., You, S.-J., Price, W.E., Nghiem, L.D. 2014. Sludge cycling between aerobic, anoxic and anaerobic regimes to reduce sludge production during wastewater treatment: Performance, mechanisms, and implications. Bioresource Technology, 155, 395-409.

[27] Smith, R.S. 2009. Organic contaminants in sewage sludge (biosolids) and their significance for agricultural recycling. Philosophical Transactions of the Royal Society A: Mathematical, Physical and Engineering Sciences, 367, 4005-4041.

[28] Stasinakis, S.A. 2012. Review on the fate of emerging contaminants during sludge anaerobic digestion. Bioresource Technology, 121, 432-440.

[29] Tadkaew, N., Hai, F.I., McDonald, J.A., Khan, S.J., Nghiem, L.D. 2011. Removal of trace organics by MBR treatment: The role of molecular properties. Water Research, 45, 2439-2451.

[30] Verlicchi, P., Zambello, E. 2015. Pharmaceuticals and personal care products in untreated and treated sewage sludge: Occurrence and environmental risk in the case of application on soil — A critical review. Science of The Total Environment, 538, 750767.

[31] Wang, L., Wijekoon, K.C., Nghiem, L.D., Khan, S.J. 2014. Removal of polycyclic musks by anaerobic membrane bioreactor: biodegradation, biosorption, and enantioselectivity. Chemosphere, 117, 722-729. 
[32] Wijekoon, C.K., Hai, I.F., Kang, J., Price, E.W., Wenshan Guo, Ngo, H.H., Cath, Y.T., Nghiem, D.L. 2014. A novel membrane distillation-thermophilic bioreactor system: Biological stability and trace organic compound removal. Bioresource Technology, 159, 334-341.

[33] Wijekoon, K.C., McDonald, J.A., Khan, S.J., Hai, F.I., Price, W.E., Nghiem, L.D. 2015. Development of a predictive framework to assess the removal of trace organic chemicals by anaerobic membrane bioreactor. Bioresource Technology, 189, 391-398. 


\section{List of Tables}

412 Table 1: Biological performance of the three digesters (average \pm standard deviation of at 413 least eight separate samples).

\begin{tabular}{|c|c|c|c|}
\hline \multirow{2}{*}{ Parameters } & \multicolumn{3}{|c|}{ Digester SRT (d) } \\
\cline { 2 - 4 } & 15 & 20 & 30 \\
\hline TS reduction (\%) & $59.3 \pm 15.0$ & $63.3 \pm 14.7$ & $68.6 \pm 11.7$ \\
\hline VS reduction (\%) & $69.3 \pm 11.8$ & $73.5 \pm 12.0$ & $75.8 \pm 8.8$ \\
\hline tCOD removal (\%) & $70.2 \pm 5.6$ & $71.9 \pm 7.8$ & $77.1 \pm 5.3$ \\
\hline sCOD removal (\%) & $49.5 \pm 18.6$ & $45.8 \pm 15.3$ & $53.4 \pm 12.1$ \\
\hline
\end{tabular}

414 


\begin{tabular}{|c|c|c|c|c|c|}
\hline \multirow{2}{*}{ Compounds } & \multirow{2}{*}{$\begin{array}{l}\text { Log D at } \\
\text { pH } 5\end{array}$} & \multicolumn{2}{|c|}{ Concentration } & \multicolumn{2}{|c|}{ Mass distribution } \\
\hline & & $\begin{array}{l}\text { Aqueous phase } \\
\text { (ng/L) }\end{array}$ & $\begin{array}{c}\text { Solid phase (ng/kg dry } \\
\text { sludge) }\end{array}$ & $\begin{array}{l}\text { Aqueous } \\
\text { phase (\%) }\end{array}$ & $\begin{array}{l}\text { Solid phase } \\
\text { (\%) }\end{array}$ \\
\hline Atenolol & -2.75 & $2,649 \pm 1,310$ & $94,000 \pm 93,000$ & 52 & 48 \\
\hline Trimethoprim & -1.33 & $1,095 \pm 263$ & $98,000 \pm 67,000$ & 29 & 71 \\
\hline Caffeine & -0.63 & $50,910 \pm 19,501$ & $910,000 \pm 497,000$ & 64 & 36 \\
\hline Paracetamol & 0.48 & $64,104 \pm 52,814$ & $898,000 \pm 843,000$ & 71 & 29 \\
\hline Primidone & 0.83 & $184 \pm 142$ & $22,000 \pm 25,000$ & 23 & 77 \\
\hline Fluoxetine & 0.83 & $192 \pm 102$ & $61,000 \pm 31,000$ & 10 & 90 \\
\hline Clozapine & 0.96 & $324 \pm 97$ & $1,699,000 \pm 4,270,000$ & 1 & 99 \\
\hline Verapamil & 0.98 & $117 \pm 38$ & $132,000 \pm 69,000$ & 3 & 97 \\
\hline Amitriptyline & 1.35 & $791 \pm 328$ & $1,023,000 \pm 2,398,000$ & 3 & 97 \\
\hline Carbamazepine & 1.89 & $5,271 \pm 1,676$ & $154,000 \pm 88,000$ & 56 & 44 \\
\hline Naproxen & 2.49 & $2,809 \pm 656$ & $23,000 \pm 23,000$ & 82 & 18 \\
\hline Diuron & 2.68 & $220 \pm 47$ & $21,000 \pm 12,000$ & 27 & 73 \\
\hline Ibuprofen & 2.81 & $12,503 \pm 4,716$ & $721,000 \pm 1,139,000$ & 40 & 60 \\
\hline Bisphenol A & 3.64 & $1,700 \pm 1,210$ & $163,000 \pm 86,000$ & 27 & 73 \\
\hline Diclofenac & 3.66 & $419 \pm 217$ & $19,000 \pm 16,000$ & 43 & 57 \\
\hline Gemfibrozil & 3.86 & $250 \pm 124$ & $24,000 \pm 13,000$ & 28 & 72 \\
\hline Triclosan & 5.34 & $10,680 \pm 4,506$ & $1,965,000 \pm 1,171,000$ & 16 & 84 \\
\hline Triclocarban & 6.07 & $9,212 \pm 5,515$ & $4,308,000 \pm 1,836,000$ & 7 & 93 \\
\hline
\end{tabular}

Table 2: Occurrence of TrOCs of primary sludge in aqueous phase and solid phase (average \pm standard deviation of samples taken every 10 days over 12 weeks). 
419 Figure 1: Methane production activities and biogas composition at SRT of 15, 20, and 30 420 days.

421 Figure 2: Concentration of TrOCs of primary sludge and digested sludge in aqueous phase 422 (error bars show the standard deviation of 12 independent samples).

423 Figure 3: Concentration of TrOCs of primary sludge and digested sludge in solid phase (error 424 bars show the standard deviation of 12 independent samples).

425 Figure 4: Mass distribution of TrOCs after anaerobic digestion at SRT of (a) 15, (b) 20, and 426 (c) 30 days. 


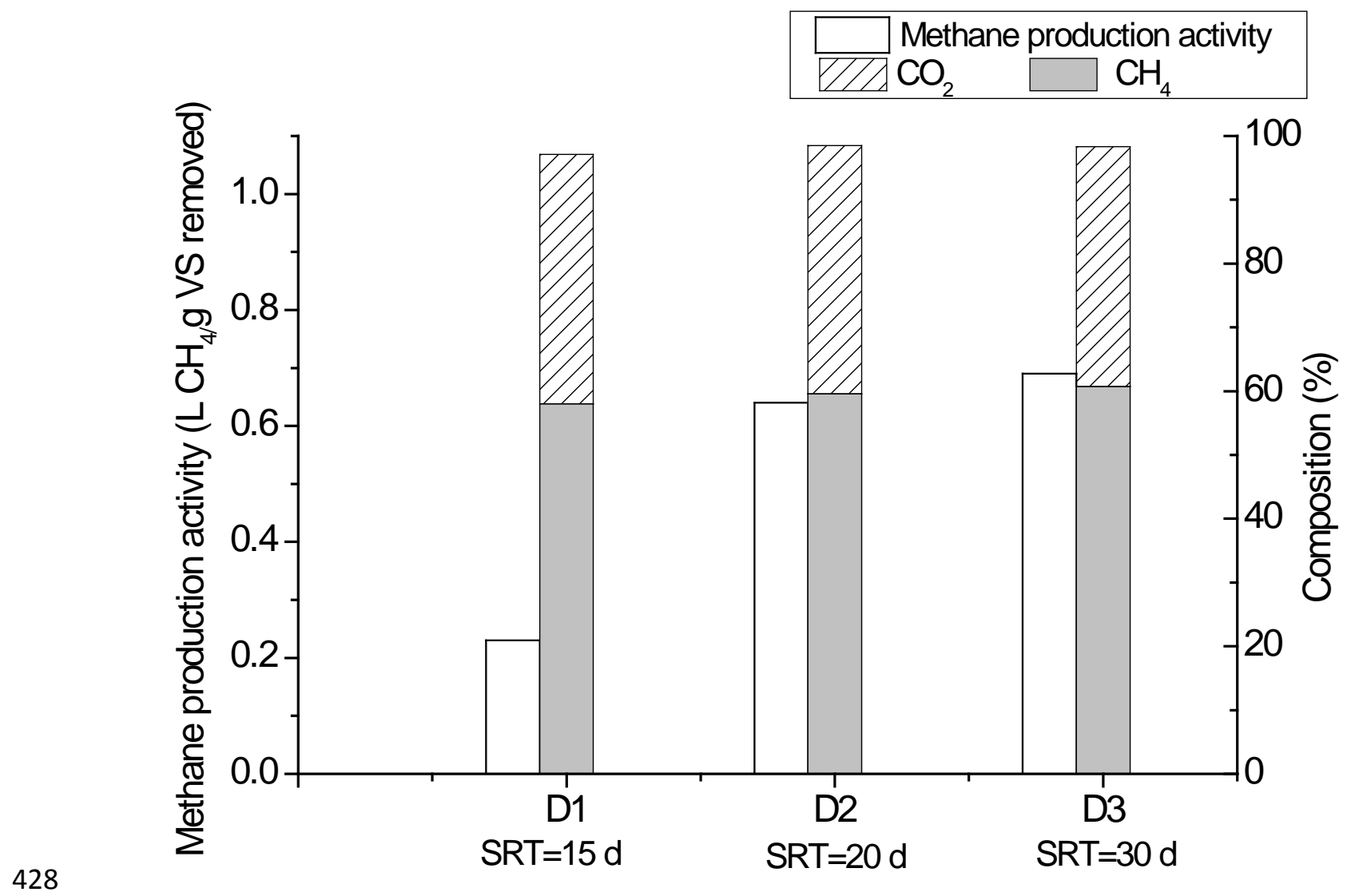

$429 \quad$ Figure 1 


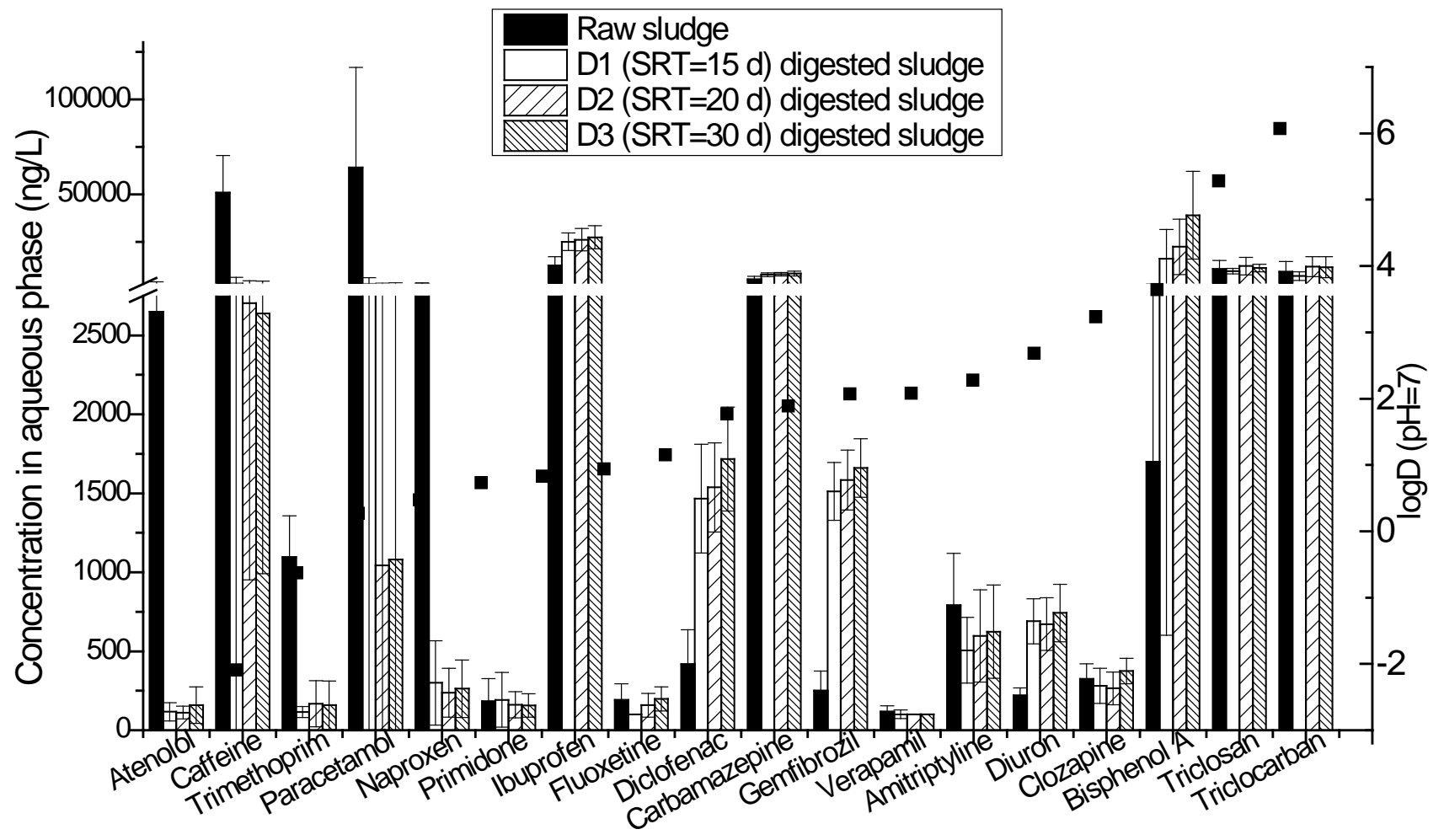

430

$431 \quad$ Figure 2 


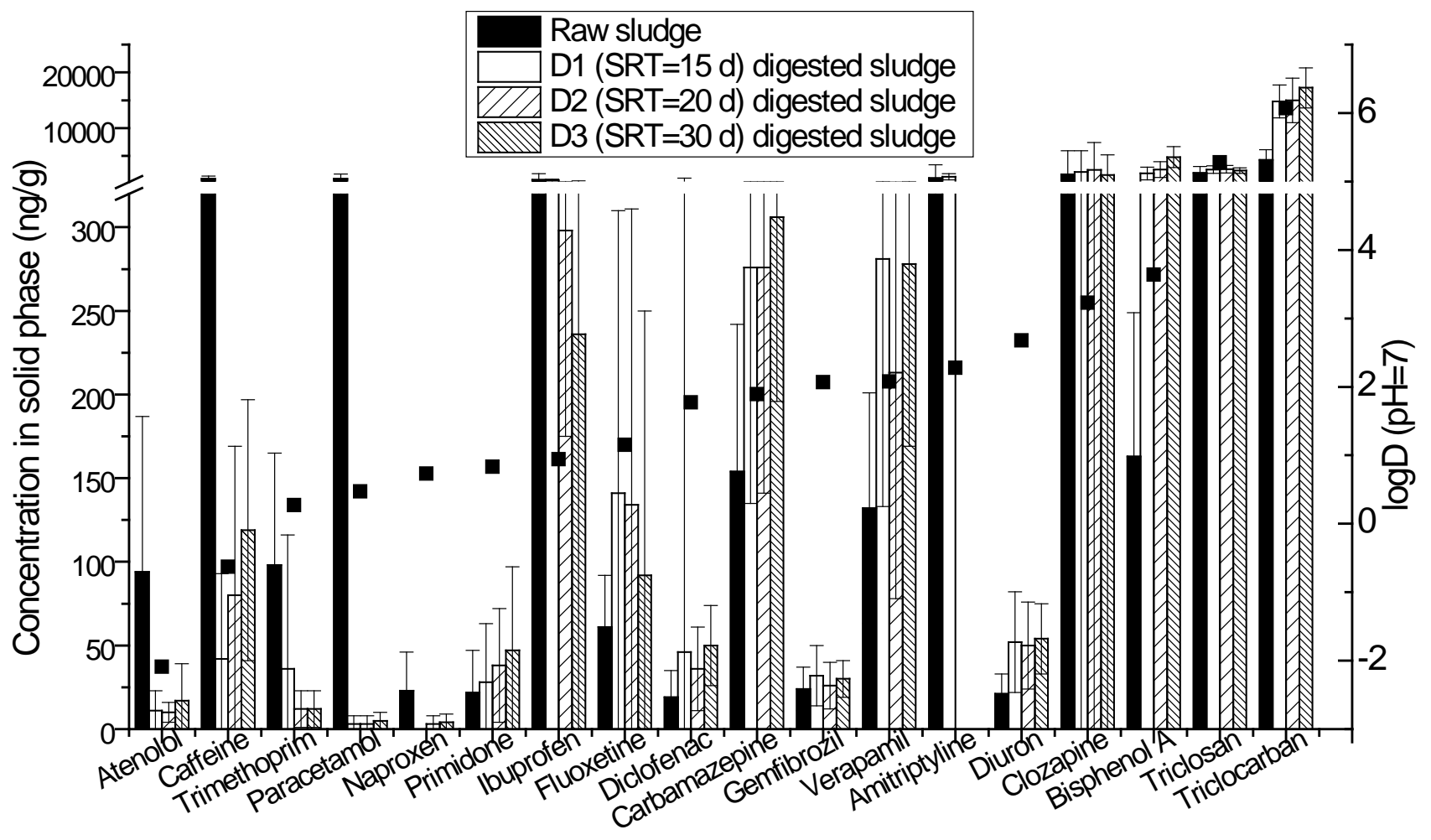

432

$433 \quad$ Figure 3 


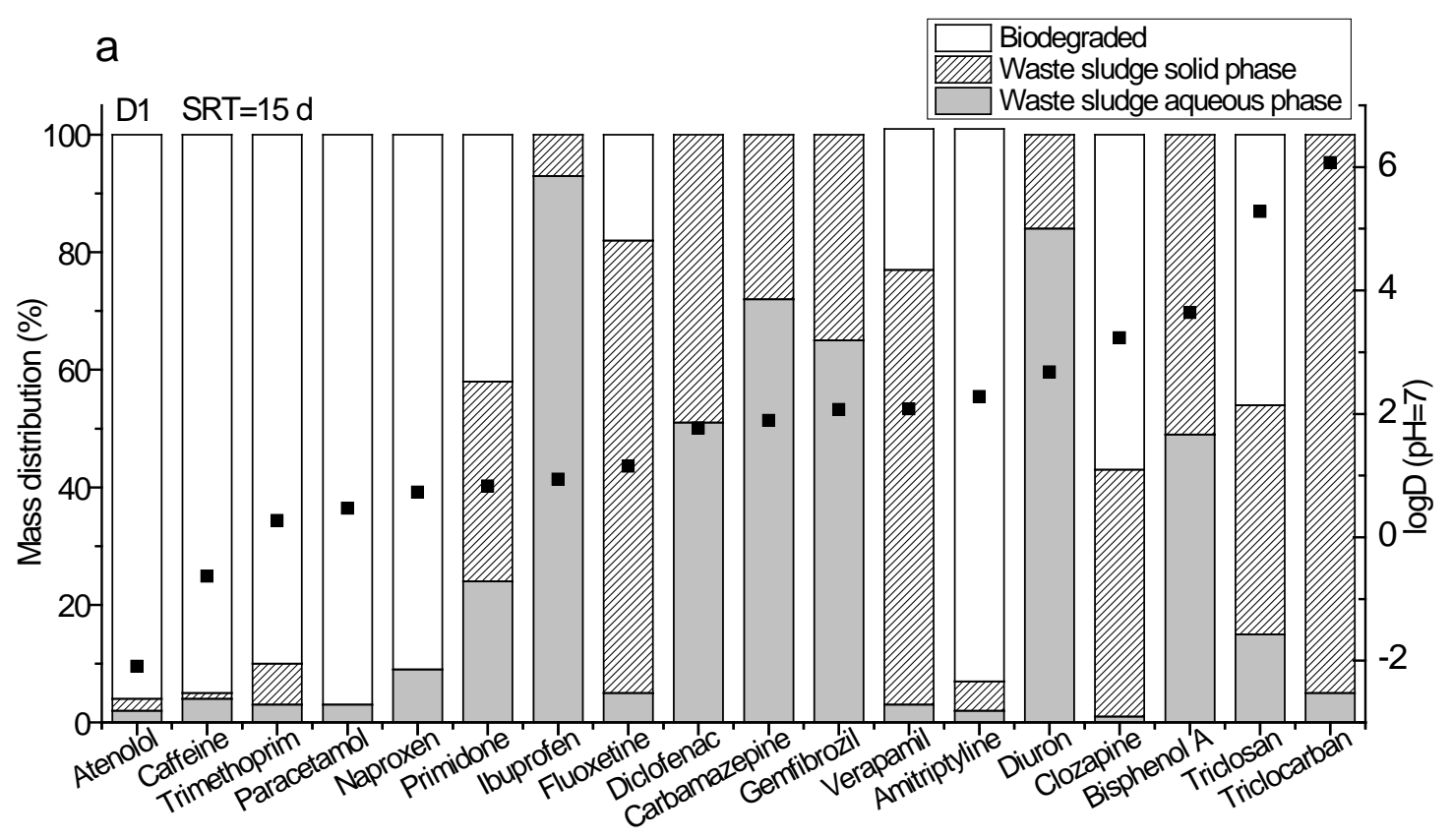

434

b

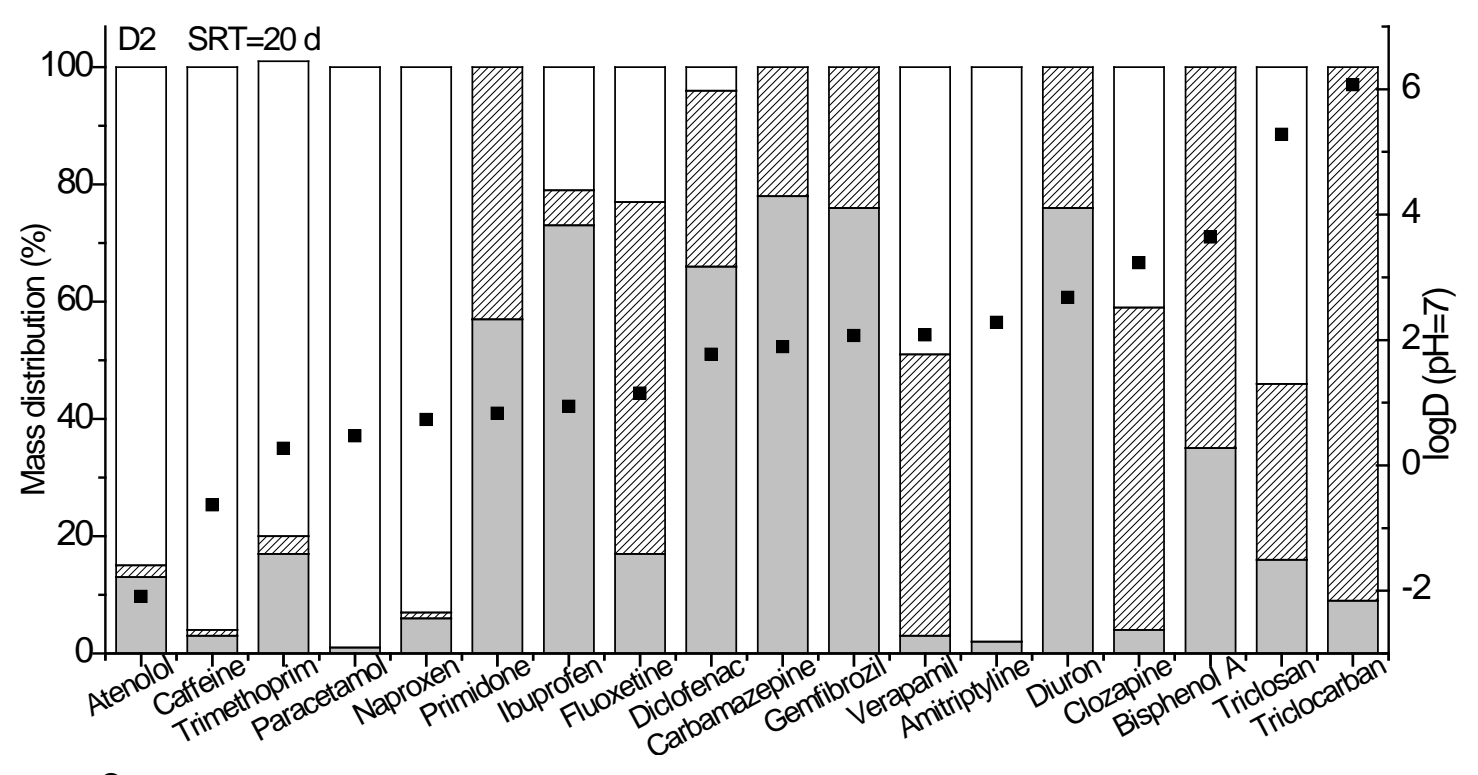

C

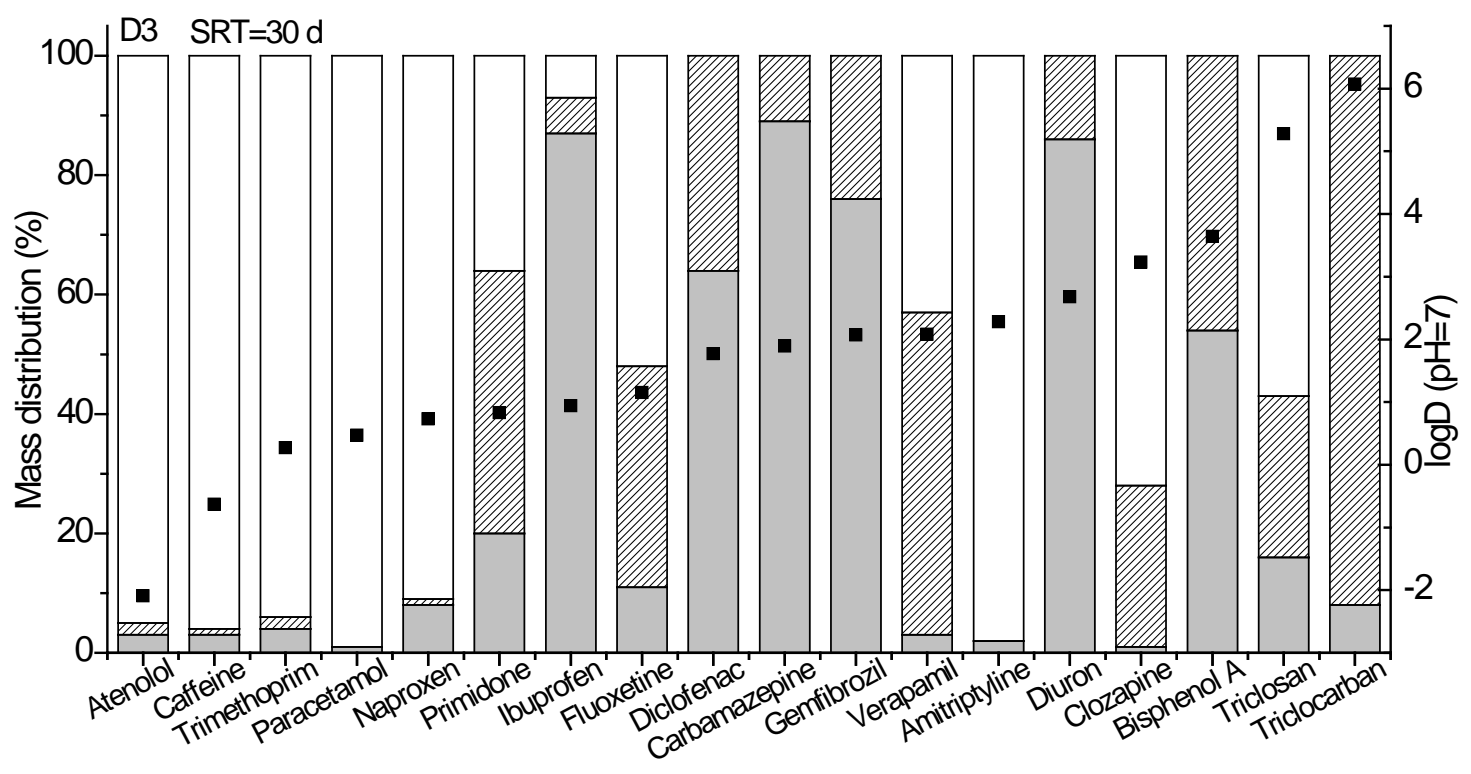

Figure 4 


\title{
Occurrence of trace organic contaminants in wastewater sludge and their removals by anaerobic digestion
}

\author{
SUPPLEMENTARY INFORMATION
}

\section{Submitted to Bioresource Technology}

Shufan Yang a , James McDonald ${ }^{\mathrm{c}}$, Faisal I. Hai ${ }^{\mathrm{a}}$, William E. Price ${ }^{\mathrm{b}}$, Stuart J. Khan ${ }^{\mathrm{c}}$, Long D. Nghiem ${ }^{a^{*}}$

${ }^{a}$ Strategic Water Infrastructure Lab, School of Civil, Mining and Environmental Engineering, University of Wollongong, Australia

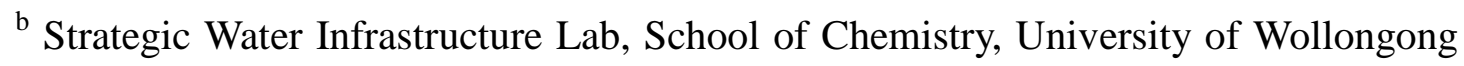
Australia

c School of Civil and Environmental Engineering, University of New South Wales, NSW 2052, Australia

\footnotetext{
* Corresponding author: longn@uow.edu.au; Ph: +61 (2) 42214590.
} 


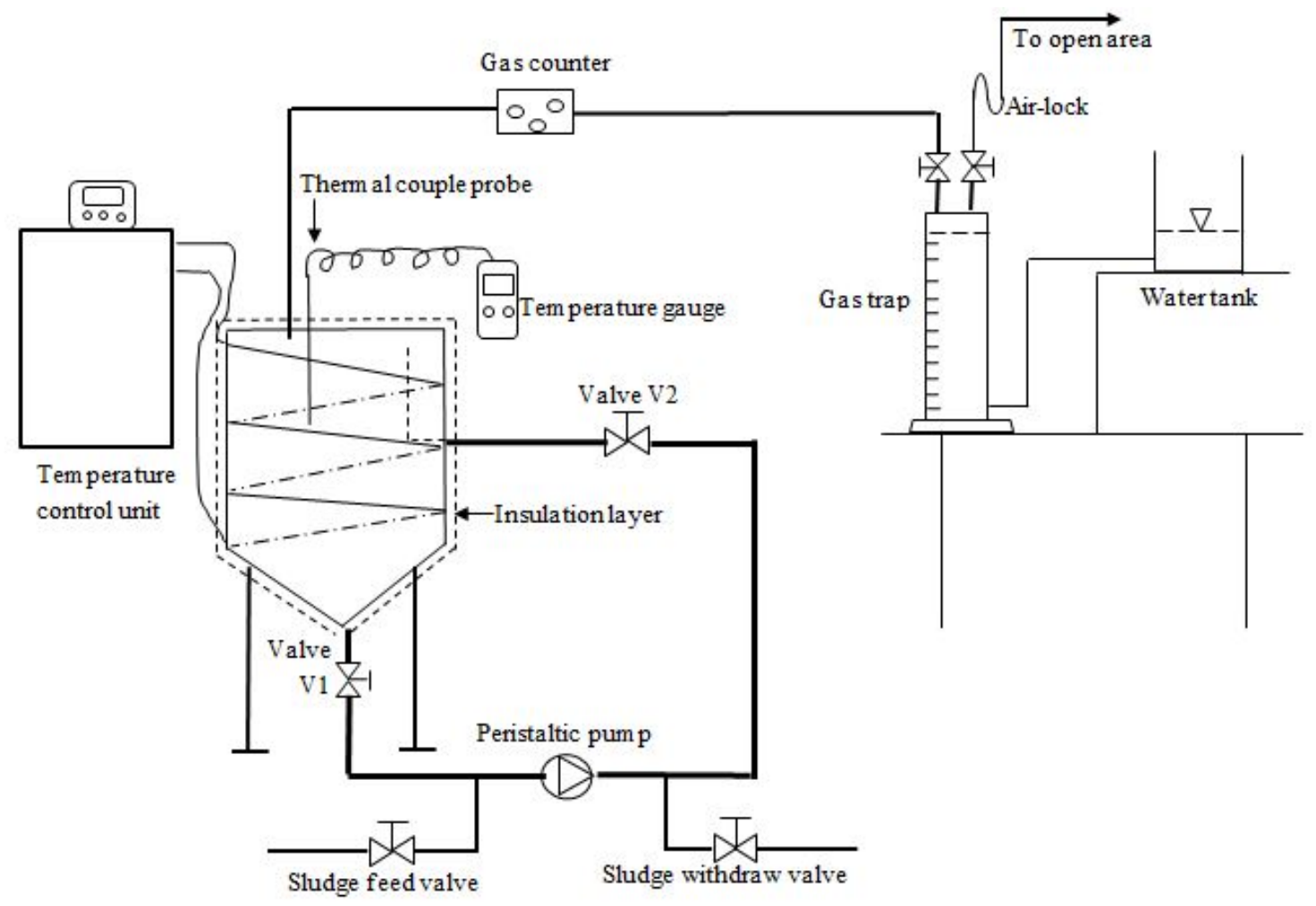

Figure S1: Schematic diagram of the anaerobic digester. 
Table S2: List compounds being monitored (isotopically labelled standards were added to the primary sludge) in this study.

\begin{tabular}{|c|c|c|}
\hline No. & Compounds & Detected in primary sludge \\
\hline 1 & Tris(2-carboxyethyl)phosphine & No \\
\hline 2 & Atenolol & Yes \\
\hline 3 & Caffeine & Yes \\
\hline 4 & Sulfamethoxazole & No \\
\hline 5 & Enalapril & No \\
\hline 6 & Ketoprofen & No \\
\hline 7 & Trimethoprim & Yes \\
\hline 8 & Paracetamol & Yes \\
\hline 9 & Meprobamate & No \\
\hline 10 & Naproxen & Yes \\
\hline 11 & Primidone & Yes \\
\hline 12 & Ibuprofen & Yes \\
\hline 13 & Triamterene & No \\
\hline 14 & Fluoxetine & Yes \\
\hline 15 & Dilantin (phenytoin) & No \\
\hline 16 & Risperidone & No \\
\hline 17 & Diclofenac & Yes \\
\hline 18 & Carbamazepine & Yes \\
\hline 19 & Gemfibrozil & Yes \\
\hline 20 & Verapamil & Yes \\
\hline 21 & Hydroxyzine & No \\
\hline 22 & Amitriptyline & Yes \\
\hline 23 & Simazine & No \\
\hline 24 & Omeprazole & No \\
\hline 25 & Atrazine & Yes \\
\hline 26 & Diuron & Yes \\
\hline 27 & Diazepam & No \\
\hline 28 & Linuron & No \\
\hline 29 & Clozapine & Yes \\
\hline 30 & Phenylphenol & No \\
\hline 31 & Bisphenol A & Yes \\
\hline 32 & Diazinon & No \\
\hline 33 & Triclosan & Yes \\
\hline 34 & Triclocarban & Yes \\
\hline 35 & 4-n-nonylphenol & No \\
\hline 36 & Polyparaben (polymer) & No \\
\hline
\end{tabular}




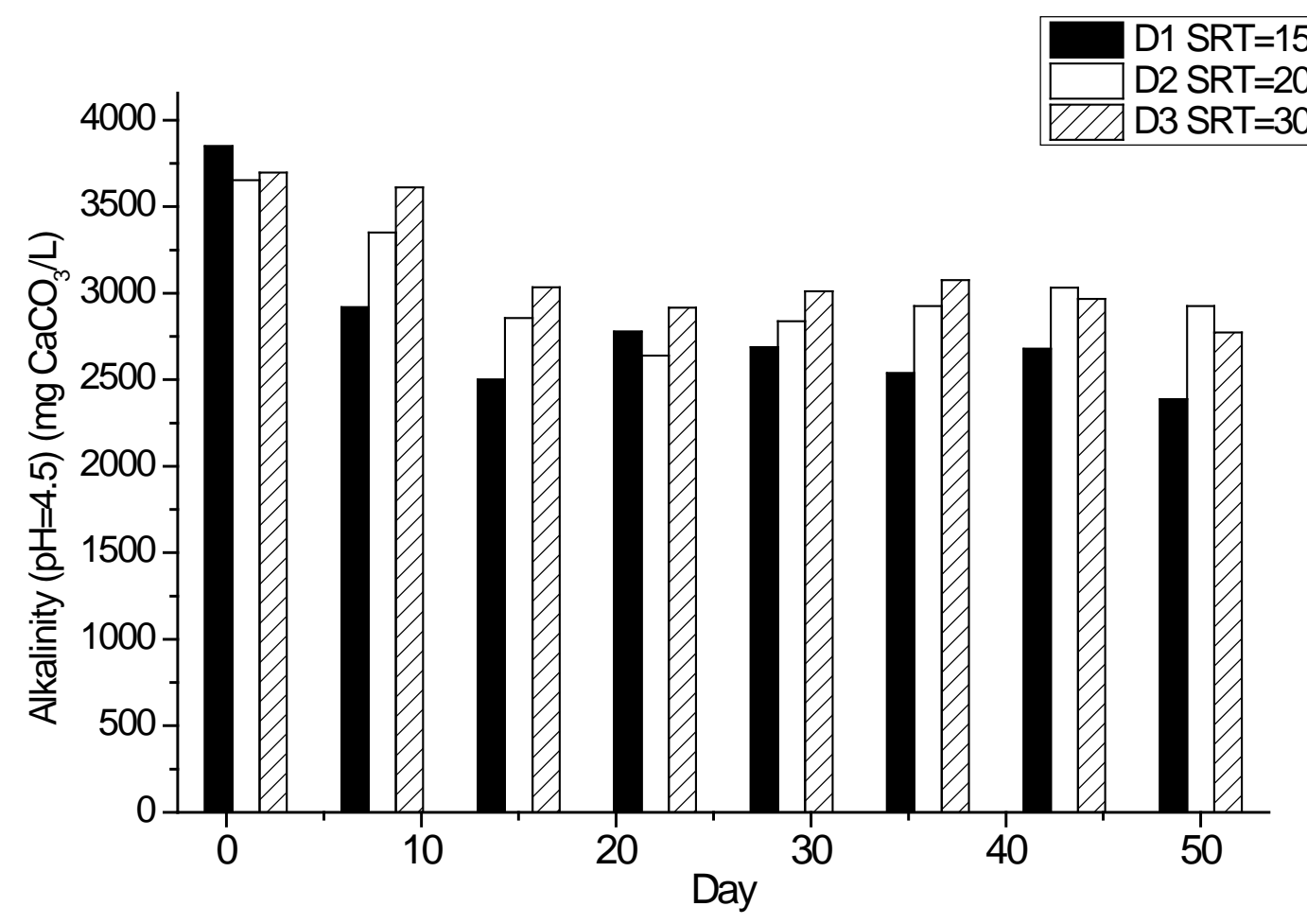

Figure S3: Alkalinity of digested sludge at three different sludge retention time of 15, 20 , and 30 days. 
Table S4: Molecular structure of the 18 TrOCs detected in the primary sludge this study.

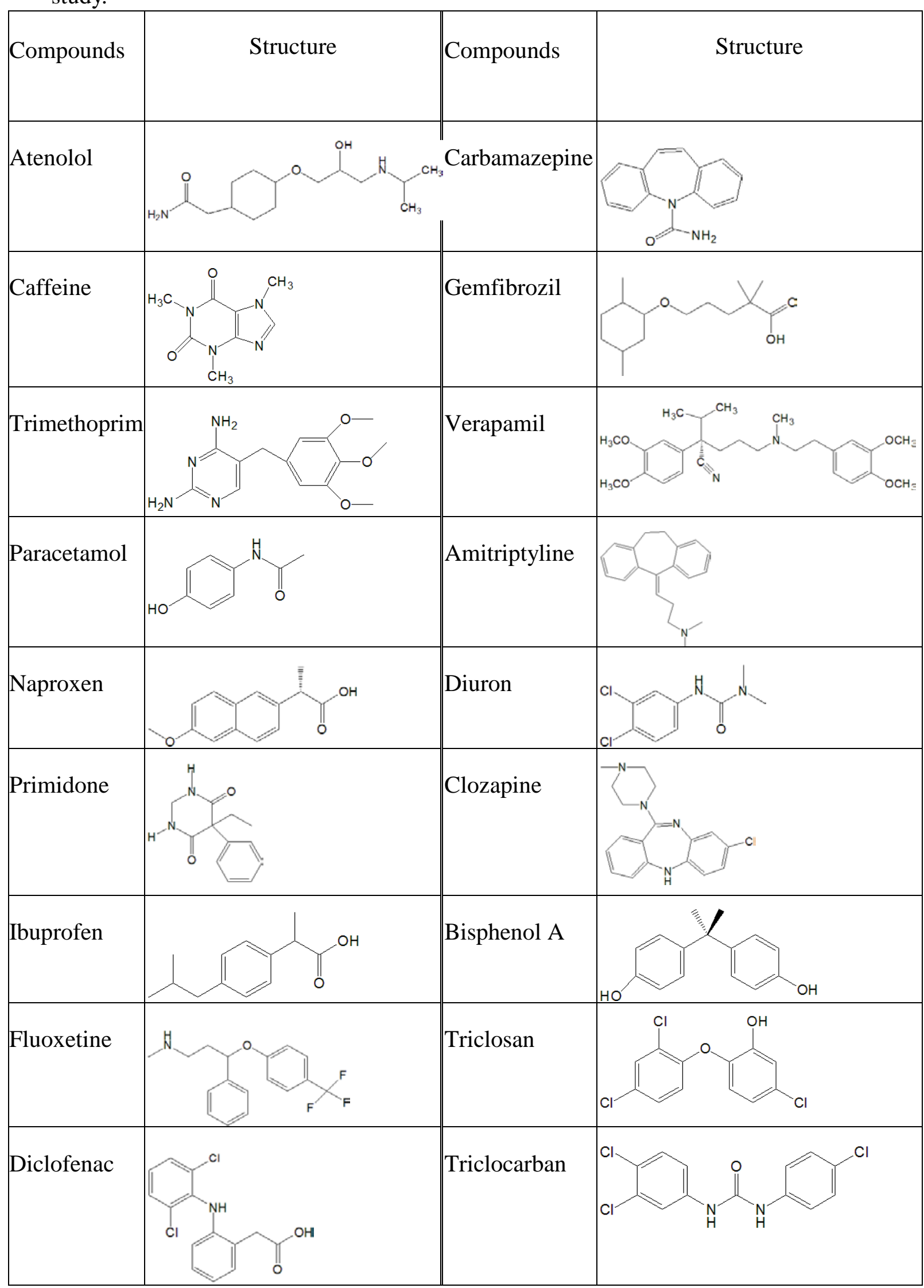


Table S5: Examples of electron donating and withdrawing functional groups.

\begin{tabular}{|l|l|}
\hline Strong electron donating functional groups & Strong electron withdrawing functional groups \\
\hline $\mathrm{O}-\mathrm{R}-\mathrm{OH}-\mathrm{NHR}$
\end{tabular}




\section{RESEARCH HIGHLIGHTS}

- 18 TrOCs were consistently detected in raw primary sludge

- These TrOCs occurred predominantly in the solid phase

- TrOC removal by anaerobic digestion was governed by their molecular structure

- An increase in SRT value led to an increase in biogas production and VS removal

- However, SRT increase did not lead to any discernible increase in TrOC removal 